\title{
SIGNIFICADO DA INTERNAÇÃO HOSPITALAR PEDIÁTRICA NA PERSPECTIVA DE PROFISSIONAIS E FAMILIARES
}

Leila Raquel Alves Mariano', Dirce Stein Backes², Silomar Ilha², Glaucia Dal Omo Nicola ${ }^{3}$, Hilda Maria Barbosa de Freitas ${ }^{4}$, Carla Lizandra de Lima Ferreira ${ }^{4}$

\begin{abstract}
RESUMO: O presente estudo teve por objetivo compreender o significado da internação hospitalar pediátrica na perspectiva de familiares das crianças e dos profissionais de enfermagem de um hospital público do Município de Santa Maria, Rio Grande do Sul. Trata-se de uma pesquisa exploratória, de caráter qualitativo. Os dados foram coletados entre os meses de agosto a novembro de 2010, por meio de entrevistas, contemplando uma questão norteadora: qual o significado da internação hospitalar para você? Os dados analisados resultaram em duas unidades temáticas: A desordem provocada pela internação e Oportunidade de estabelecer novas formas de organização. Ao mesmo tempo em que o processo de internação representa uma desordem familiar e social para os usuários, também pode apresentar-se como oportunidade de promover a educação em saúde, do ponto de vista dos profissionais de enfermagem.

PALAVRAS-CHAVE: Criança hospitalizada; Família; Enfermagem.

\section{THE MEANING OF PAEDIATRIC HOSPITALIZATION FORM THE PERSPECTIVE OF HEALTHCARE PROFESSIONALS AND FAMILY MEMBERS}

\begin{abstract}
This study aimed to increase understanding of paediatric hospitalization from the perspective of the members of the children's families and the nursing professionals in a state hospital in the town of Santa Marial, in the state of Rio Grande do Sul in Brazil. It is exploratory research with a qualitative character. The data was collected between August and November 2010through interviews, with a guiding question: what does hospitalization mean to you? Analyzed, the data produced two thematic units: The disorder caused by hospitalization and The opportunity to establish new forms of organization. While the process of hospitalization represents family and social disorder for the service users, at the same time it can appear as an opportunity to promote health education from the point of view of the nursing professionals.

KEYWORDS: The hospitalized child; Family; Nursing.

\section{SIGNIFICADO DE LA INTERNACIÓN HOSPITALAR PEDIÁTRICA EN LA PERSPECTIVA DE PROFESIONALES Y FAMILIARES}

RESUMEN: Este estudio tuvo el objetivo de comprender el significado de la internación hospitalar pediátrica en la perspectiva de familiares de los niños y de los profesionales de enfermería de un hospital público del Municipio de Santa Marial, Rio Grande del Sul. Esta es una investigación exploratoria, de carácter cualitativo. Los datos fueron recogidos entre los meses de agosto y noviembre de 2010, por medio de entrevistas, contemplando una cuestión llave: ¿Cuál el significado de la internación hospitalar para usted? Los datos analizados resultaron en dos unidades temáticas: El desorden provocado por la internación y Oportunidad de establecer nuevas formas de organización. Mientras el proceso de internación representa un desorden familiar y social para los usuarios, también puede presentarse como oportunidad de promover la educación en salud, según el punto de vista de los profesionales de enfermería.

PALABRAS-CLAVE: Niño hospitalizado; Familia; Enfermería.

${ }^{1}$ Enfermeira Assistencial do Hospital de Caridade Dr. Astrogildo de Azevedo, Santa Maria-RS.

${ }^{2}$ Enfermeira. Doutora em Enfermagem. Professora do Curso de Graduação em Enfermagem do Centro Universitário Franciscano UNIFRA. Coordenadora do Grupo de Estudos e Pesquisa em Empreendedorismo Social da Enfermagem e Saúde - CEPESES.

${ }^{3}$ Acadêmica de Enfermagem do UNIFRA. Membro do GEPESES e do Grupo de Estudos e Pesquisa em Enfermagem e Saúde - GEPES. ${ }^{4}$ Enfermeira. Professora do Curso de Graduação em Enfermagem do UNIFRA. Doutoranda em Enfermagem pelo Dinter Novas Fronteiras - UNIFESP/UFRJ/UFSM. Membro do GEPESES. 


\section{INTRODUÇÃO}

O Programa Nacional de Humanização da Assistência Hospitalar (PNHAH) foi implantado pelo Ministério da Saúde, em 2002, na tentativa de contribuir para a transformação dos modelos tradicionais de gestão e atenção à saúde, bem como estimular as práticas de cogestão dos processos de trabalho e atender as demandas manifestadas pelos trabalhadores e usuários dos serviços de saúde. Mais tarde, o Programa passou a se caracterizar como a Política Nacional de Humanização (PNH), a fim de ampliar os processos interativos, superar as práticas pontuais e fomentar a participação de todos os usuários ${ }^{(1)}$.

Nesse contexto, a humanização pode ser entendida como um processo cultural, que implica na valorização dos diferentes sujeitos envolvidos na produção dos cuidados em saúde, sejam eles usuários, trabalhadores e/ ou gestores. Assim a humanização requer o fomento da autonomia e do protagonismo desses sujeitos, no sentido de aumentar o grau de corresponsabilidade dos atores sociais. Este estabelecimento de vínculos solidários e de participação coletiva, no processo de gestão, denota a identificação das necessidades sociais de saúde ${ }^{(1)}$.

Os princípios norteadores da PNH são o acolhimento, a autonomia, o protagonismo e a corresponsabilidade, os quais servem como base de mudança na relação entre funcionários e usuários. Essa política prioriza as práticas de saúde, construídas com base no modelo biomédico, que é o principal referencial epistemológico para a formação de profissionais ${ }^{(2)}$.

Como forma de acolhimento, pode-se mencionar as tecnologias leves, sendo as principais ferramentas do cuidado em saúde, e que se consolidam pela formação do vínculo profissional-usuário. Nessa perspectiva, acolher significa muito mais que realizar um atendimento técnico de qualidade, ou seja, estabelecer relações de confiança mútua, a partir do trabalho em equipe na busca de aprimorar o cuidado e consolidar os direitos e deveres dos usuários e suas famílias ${ }^{(3)}$.

Em se tratando de uma criança hospitalizada, vários fatores contribuem para o agravamento da situação. O familiar se envolve de forma efetiva e afetiva e, frequentemente, ocorrem abalos de todas as ordens. Neste delineamento, a equipe de saúde, sobretudo a de enfermagem, precisa estar devidamente sensibilizada e instrumentalizada para acolher e compreender a criança em condição vulnerável - bem como a seus familiares que estão susceptíveis ao desgaste físico e emocional - transmitindo segurança em um atendi- mento humano e resolutivo. No momento da internação da criança, os seus familiares apresentam sentimentos como de revolta, medo e insegurança, devido ao estresse que este momento proporciona, gerando uma desestruturação familiar ${ }^{(4)}$.

Para tanto, compete ao profissional de enfermagem avaliar o contexto experienciado pela criança e seus familiares frente à hospitalização, a fim de amenizar a dor e sofrimento, bem como assegurar um atendimento resolutivo que miniminize o sofrimento e o medo dos pais e da criança pelo desconhecido. A reflexão da prática assistencial é de grande valia para que os profissionais envolvidos no cuidado em unidade pediátrica sejam condutores das estratégias de humanização e do acolhimento à criança e sua família.

Justifica-se a relevância do presente estudo, uma vez que ele pode auxiliar na compreensão das dificuldades encontradas no processo de internação hospitalar pediátrica, facilitando o engajamento de condutas humanas e éticas como forma de tecnologia leve. Percebe-se que o enfermeiro possui uma importante função no desenvolvimento de práticas que considerem a humanização do cuidado em saúde, visto ser ele o profissional que permanece a maior parte do tempo próximo da criança hospitalizada, sendo referência nos diferentes eventos que ocorrem durante a internação.

Nesse contexto, objetivou-se compreender o significado da internação hospitalar pediátrica na perspectiva de familiares e profissionais de enfermagem.

\section{METODOLOGIA}

Trata-se de uma pesquisa exploratória, descritiva, de caráter qualitativo, realizada de agosto a outubro de 2010 em um hospital municipal de médio porte, localizado em Santa Maria, Estado do Rio Grande do Sul, o qual possui um total de 130 leitos. A Unidade Pediátrica tem 25 leitos e um quadro funcional de dez técnicos em enfermagem, um enfermeiro gerente e quatro enfermeiras supervisoras.

Os critérios de inclusão dos sujeitos foram: pertencer à equipe de enfermagem e ser familiar e/ou cuidador da criança hospitalizada na Unidade Pediátrica no período do estudo. Participaram da pesquisa cinco enfermeiros, três técnicos de enfermagem e cinco familiares, os quais assinaram o Termo de Consentimento Livre eEsclarecido.

Os dados foram coletados por meio de entrevista semiestruturada, contemplando uma questão aberta, com vistas a compreender o significado da internação hospitalar pediátrica na percepção do sujeito da pesquisa. Manteve-se 
o anonimato dos depoentes e os mesmos foram identificados pela letra "U", referente ao Usuário (familiar), e "P" referente ao profissional, ambas seguidas de algarismo numérico, conforme ordem de entrevista.

Os dados foram analisados e categorizados seguindo a análise de conteúdo ${ }^{(5)}$, a partir de uma pré-análise (organizando o material coletado e sistematizando as idéias por meio de leitura meticulosa das respostas obtidas na entrevista) e, a seguir, a categorização das unidades de registro.

Foram considerados os preceitos éticos e legais que envolvem a pesquisa com seres humanos, conforme resolução 196/96 do Ministério da Saúde ${ }^{(6)}$; o projeto de pesquisa foi aprovado pelo Comitê de Ética em Pesquisa do Centro Universitário Franciscano, protocolo n. 089.2010.2.

\section{RESULTADOS}

A análise dos depoimentos possibilitou emergir duas categorias: A desordem provocada pela internação e Oportunidade de estabelecer novas formas de organização.

\section{Desordem provocada pela internação}

Para os familiares que acompanham a criança no processo de internação hospitalar este momento representa, inicialmente, uma desordem emocional, pelo medo do desconhecido e necessidade de se adaptar a uma nova realidade. $\mathrm{O}$ medo é relevante, não apenas por causa da separação dos demais membros familiares, mas pelo problema financeiro, a incerteza ao se deparar com o desconhecido e presenciar o sofrimento da criança, conforme as falas:

Eu fiquei triste, chocada, porque a doutora disse que ele estava com pneumonia e dai ele começou a se atacar dos nervos porque ele tinha que ficar no hospital. Mas dai eu me contive, porque ele já estava chorando e eu chorar também não ia dar certo [...] é só eu com ele aqui não tem ninguém pra ficar junto comigo. e eu trabalho e gasto passagem, né? A gente tem que buscar em casa, são quatro passagens, não dá. Então, tem que ficar aqui, esperar até quando liberarem ele. Enquanto isso, eu vou sofrendo e lutando junto com ele. (U1)

Meu filho nunca foi internado [...] ele é muito pequenininho. [...] eu tenho dois guri, dois filhos em casa, tão um em cada casa de outros [...] pra mim é ruim ficar aqui [o outro filho] não fica com ninguém, é só comigo. Com a minha irmã também não fica. E mama no peito, dai pra mim é ruim ficar internada com ele [...] capaz da gente ficar doente junto [...]. (U2)

Por outro lado, a internação de uma criança se mostra, para os profissionais de enfermagem, uma oportunidade para exercitar a educação em saúde:

A internação hospitalar na pediatria, eu vejo como uma oportunidade da gente educar as mães, não só pra tratar a doença, mas também dar orientações, pois a cultura que eles trazem de casa sobre o banho, às vezes, pensam que criança não pode tomar banho todo dia, pois acham que a criança poderá adoecer. Ai, explicamos, orientamos para tentar mudar um pouco esta cultura que eles têm e aproveitar para ver a criança como um todo. A gente já vê o peso, carteirinha de vacinação, toda a questão social, o que aconteceu e porque internou. (P5)

Para mim a internação é uma oportunidade de ver a criança, dar orientações, porque como a nossa clientela é de pessoas que não costumam levar as crianças no pediatra, conforme deveriam, torna-se importante fazê-las na internação. (P1)

Bom, o significado da internação, a palavra correta, normalmente ninguém gosta, porque é significado de estar doente, não estar bem, ter que ficar no hospital. Mas, nós, como uma equipe multiprofissional, temos a oportunidade de orientar as pessoas mais leigas quanto à saúde, higiene e nutrição. Conseguimos ajudar essa pessoa a não só se prevenir ou curar doenças, mas sim, orientar uma escovação de dente, alimentação correta. Nos envolvemos muito na vida das pessoas. É uma psicologia estar dentro da pediatria! Nessas orientações é indispensável a equipe interdisciplinar. (P2)

\section{Oportunidade de estabelecer novas formas de or- ganização}

Para os profissionais de enfermagem o processo de internação representa a possibilidade de adquirir novos conhecimentos e o exercício de saberes adquiridos na formação profissional:

Eu vou falar mais pela pediatria, que é onde eu tenho mais conhecimento agora, porque geralmente é a mãe que fica mais em contato. A família fica desestruturada, então, internação é um termo bem ruim pra quem tem que passar por isso. Eu acho que no momento que você 
é recebido precisa ser acolhido. Todos têm o direito de ser bem tratados, independente de cor, raça ou valores. E também tem que ter um restabelecimento mais breve possivel e a equipe em si tem que estar integrada, dar um bom atendimento. Isso não vai curar a doença, mas vai, pelo menos, amenizar o que a pessoa está passando no momento. (P3)

Procuramos sempre dar o melhor atendimento ao cliente e não só como momento ruim. Por exemplo, procuramos ver todo o tipo de contato que vamos ter com o paciente, de diálogo, crescimento profissional e pessoal, tanto pro paciente quanto para nós, profissionais da área da saúde. (P7)

Entendo que para o paciente o momento de internação, mesmo que seja para melhoria, é visto de maneira assustadora, é um momento de aflição, conflitos, incertezas e dúvidas. Aí está a importância do profissional: esclarecer, conversar, fazer o processo de educação em saúde nesta situação. (P8)

Existem internações hospitalares que são alegres, são felizes, como o nascimento de uma criança, ou alguma cirurgia de reconstituição. mas, assim mesmo, gera em toda a família um momento de transtorno e de aflição, por ser um procedimento cirúrgico em que é necessária hospitalização, mudando sua rotina diária como alimentação, sono, repouso, tendo que se adaptar a essa rotina diferente, perdendo a sua autonomia e privacidade no momento que divide o quarto com outras pessoas jamais vistas antes. (P4)

As falas dos profissionais mostram um cenário que inclui o sentimento do familiar frente ao desconhecido no ambiente hospitalar, e a relevância do apoio emocional. Observa-se que ocorre um momento de satisfação profissional, pois podem ser utilizadas experiências vivenciadas no processo de formação frente às pessoas que sofrem alterações comportamentais, acrescidas pela alteração psicológica apresentada pelo familiar que necessita adaptar-se à nova situação.

\section{DISCUSSÃO}

A hospitalização para criança é um momento complexo que exige acompanhamento da família e de profissionais que compreendam seus sentimentos e as reações provocadas pelo contexto novo e ameaçador. É preciso perceber a criança como ser vulnerável, tanto na saúde quanto na hospitalização, pois ela necessita ser cuidada por pessoas que sejam referência no seu viver, para acreditar que é amada e sentir-se segura no ambiente onde está inserida ${ }^{(7)}$.

A criança hospitalizada vivencia um processo no qual é separada das pessoas de seu convívio social e afastada de sua rotina diária, ficando fragilizada. Esse fato acarreta aos familiares, em especial à mãe, desgaste físico e psicológico, além de sentimentos como medo, insegurança e depressão ${ }^{(8)}$. Dessa forma, a vivência da doença do filho configura-se como processo de transição, no qual os familiares necessitam enfrentar e adaptar-se à nova situação ${ }^{(9)}$. Como resultado, os familiares da criança hospitalizada, em especial a mãe, podem apresentar-se ansiosos, pouco flexíveis e espontâneos nas relações pessoais, passando a interpretar mal os acontecimentos e comunicações verbais ${ }^{(10)}$.

É fundamental que a equipe de enfermagem reconheça a importância da manutenção dos vínculos e do cuidado com a família; é essencial que os profissionais tenham dedicação, atenção e, principalmente, a interrelação dos saberes e fazeres, a fim de auxiliar no enfrentamento e adaptação a esta nova situação. A mãe também exerce um papel importante no tratamento e recuperação do filho quando presente, colaborando para minimizar a ansiedade, o que, por sua vez, contribui para uma intervenção profissional mais efetiva e humana ${ }^{(11)}$.

A hospitalização de uma criança afeta tanto aos pais como aos profissionais da área da saúde, em especial da enfermagem, pelo convívio constante com a criança. Assim, o enfermeiro, junto à equipe multiprofissional, deverá por em prática medidas de prevenção e promoção da saúde para auxiliar na hospitalização infantil ${ }^{(10)}$.

O entendimento das habilidades apreendidas pela família durante a hospitalização da criança é um aspecto que provê a aproximação entre a experiência da doença, a condição familiar e o processo de cuidado em enfermagem, o que auxilia o enfermeiro a planejar intervenções tanto às particularidades como ao potencial das famílias. Nesse sentido, as potencialidades da família devem ser percebidas para o cuidado da criança, em um processo integrado entre estes familiares e os profissionais de saú$\mathrm{de}^{(12)}$. A atenção psicoemocional, que deve ser oferecida como suporte aos acompanhantes, incentiva a busca crescente que os capacite também ao cuidado ao lado das práticas efetivas dispensadas às crianças internadas, desde o acolhimento até a alta hospitalar.

Cuidar de uma criança durante a hospitalização, distante de seu contexto familiar, torna-se um processo complexo que exige cuidados físicos, emocionais e sociais. 
A equipe de enfermagem, durante o cuidado, precisa favorecer alternativas que facilitem a comunicação, o relacionamento e a compreensão do contexto. Ela necessita transcender a ideia ou foco de atenção à doença como um fim em si mesma; a criança é um ser humano, uno e autônomo, por isso capaz de fazer escolhas e organizar-se ou reorganizar-se, a partir das demandas em que implicam o cuidado ${ }^{(13)}$. A equipe necessita, em suma, estar consciente das formas peculiares de sentir e perceber a criança, estabelecendo uma relação autêntica, um vínculo de confiança com a criança e com o familiar, valorizando a individualidade e intersubjetividade de cada caso.

Portanto, o enfermeiro, por ser reconhecido como elemento articulador e integrador dos diferentes saberes, sobretudo por estar mais próximo e estabelecer vínculos efetivos com a criança e familiares, pode ser um interlocutor no protagonismo das práticas de saúde que valorizem a dimensão do humano durante a doença ${ }^{(14)}$.

\section{CONSIDERAÇÕES FINAIS}

O estudo evidenciou que é preciso consolidar o desafio de trabalhar com questões referentes ao acolhimento e à humanização no processo de internação hospitalar tendo como subsídio um novo olhar. Este direcionado não somente para o tratamento de doenças, mas para questões que repensem a hospitalização pediátrica como causadora de inúmeras aflições, tanto à criança hospitalizada, quanto para seu familiar. Neste contexto,oportuniza-se resgatar o comprometimento com a promoção da saúde em um contexto ampliado, visando o viver saudável dos usuários.

O cuidado realizado aos familiares foi visto pelos profissionais como forma de promover educação em saúde, orientando quanto aos cuidados a serem dispensados à criança. Foi possível perceber que os profissionais reconhecem os pais como coadjuvantes no tratamento, visto que sua presença ameniza ansiedades na criança.

Observou-se, também, que em decorrência das mudanças que a internação acarreta no cotidiano da criança e familiares, estes se sentem angustiados, apreensivos, passíveis de desenvolver processos psicopatológicos. A hospitalização da criança gera no familiar uma sensação psicoemocional que nem sempre pode ser controlada, por conta da afetividade que envolve o paciente e aquele que o acompanha ao longo da internação. Esse conflito decorre, na maioria das vezes, pela experiência frente ao desconhecido, ocasionado pela mudança repentina de estar compelido a se encontrar em um ambiente que, inicialmente, se mostra hostil, e pela necessidade de adequação às rotinas institucionais. Nesse contexto, o profissional pode estabelecer uma troca de conhecimentos e conquistar a confiança dos usuários por meio do vínculo estabelecido.

\section{REFERÊNCIAS}

1. Backes DB, Lunardi Filho WD, Lunardi VL. A humanização hospitalar como expressão da ética. Rev Latino-Am Enfermagem. 2006;14(1):132-5.

2. Alves CA, Deslandes SF, Mitre RA. Desafios da humanização no contexto do cuidado de enfermagem pediátrica de média e alta complexidade. Interface. Comunicação, Saúde, Educação. 2009;13(Supl 1):S581-94.

3. Moraes SDTA, Buchalla CM, Valenti VE, Leite L, Tanaka ACA, Macedo Júnior H, et al. Acolhendo o acolhedor: o caminho mais curto para a humanização da assistência. Rev Bras Crescimento Desenvolv Hum. 2009;19(3):393-402.

4. Gomes GC, Erdmann AL. O cuidado compartilhado entre a família e a enfermagem à criança no hospital: uma perspectiva para sua humanização. Rev Gaúch Enferm. 2005;26(1):20-30.

5. Bardin L. Análise de conteúdo. $5^{\mathrm{a}}$ ed. rev. atual. Lisboa: Edições; 2009.

6. Ministério da Saúde(BR). Conselho Nacional de Sáude. Dispõe sobre diretrizes e normas regulamentadoras de pesquisa em seres humanos. Resolução n. 196/96 de 10 de outubro de 1996. Brasília: Ministério da Saúde; 1996.

7. Medeiros HMF, Motta MGC. Existir de crianças com aids em uma casa de apoio: compreensões à luz da enfermagem humanística. Rev Gauch Enferm. 2008;29(3):400-7.

8. Forte TL, Sata CM. Programa família participante: a humanização hospitalar como resgate da dignidade, exercício da cidadania e transformação da gestão hospitalar. Curitiba: Associação Hospitalar de Proteção a Infância Dr. Raul Carneiro/ Hospital Pequeno Príncipe; 2006.

9. Zagonel IPS, Martins M, Pereira KF, Athayde J. O cuidado humano diante da transição ao papel materno: vivências no puerpério. Rev Eletr Enferm. 2003;5(2):24-32.

10. Schmitz EMRA. Problemática da hospitalização infantil: aspectos psicológicos. In: Schmitz EMR, organizador. A enfermagem em pediatria e puericultura. São Paulo: Atheneu; 1989. p. 187. 
11. Pereira MIM, Graças EM. A co-existência com os familiares dos pacientes hospitalizados: experiência do enfermeiro no seu mundo-vida profissional. REME Rev Min Enferm. 2003;7(2):93-101.

12. Silveira AO, Angelo M, Martins SR. Doença e hospitalização da criança: identificando as habilidades da família. Rev Enferm UERJ. 2008;16(2):212-7.

13. Freitas HMB, Backes DS, Pereira ADA, Ferreira CLL, Marchiori MRC, Souza MHT, et al. Significados que os profissionais de enfermagem atribuem ao cuidado de crianças institucionalizadas com aids. Texto \& Contexto Enferm. 2010;19(3):511-7.

14. Freitas HMB, Pereira AD, Ferreira CLL, Backes DS, Marchiori MRCT, Souza MHT, et al. Compreendendo o ser familiar de criança com vírus da imunodeficiência humana/síndrome da imunodeficiência adquirida pelo olhar da complexidade. Acta Paul Enferm. 2010;23(5):597-602. 